\title{
Inhibitory Effects of Cortex Dictamni Aqueous Extract on Dipeptidyl Peptidase I and Chymase Activities and the Screening of Active Ingredients in Cortex Dictamni Based on Molecular Docking Technique
}

\author{
Qi Wang, Tao Wei, Xiaoying Zhou \\ School of Pharmacy, Changzhou University, Jiangsu, 213164 China \\ E-mail: xiaoyingzhou@cczu.edu.cn
}

Received: October 21, 2020 Accepted: December 9, 2020

doi:10.5296/jbls.v12i1.18073 URL: https://doi.org/10.5296/jbls.v12i1.18073

\begin{abstract}
Dipeptidyl peptidase I (DPPI) and chymase, the granulo-proteases produced and released by mast cells, are important targets of anti-inflammatory drug research and development. Cortex Dictamni is a definite nature drug with anti-inflammatory activity, but the mechanism is unclear and effects of Cortex Dictamni on DPPI and chymase are unknown. This study focuses on effects of Cortex Dictamni aqueous extract (CDAE) on DPPI and chymase activities using cell model, bio-molecular interactions and the Molecular docking study by Discovery Studio (DS) analysis. The results showed that CDAE could significantly inhibit DPPI and chymase activities in vitro and in living rat spleen lymphocytes. Molecular docking simulation demonstrated that Troxerutin, the one of the active compounds of Cortex Dictamni, formed a hydrogen bond with amino acid ILE429 and a strong hydrophobic interaction with TYR64 CYS234 PRO279 ALA382 of DPPI. These interactions allow Troxerutin to form a stable complex with the DPPI, implicating that Troxerutin might be a potential natural inhibitor of DPPI. Dictamnoside M, another active compound of Cortex Dictamni formed hydrogen bonds and hydrophobic interactions within the binding pocket of chymase domain and form a stable complex with the chymase. Dictamnoside $M$ maybe a potential natural inhibitor of chymase. This study suggested a new nature inhibitor Cortex Dictamni and its active components with the anti-inflammatory effects.
\end{abstract}

Keywords: Cortex Dictmni, Dipeptidyl peptidase I, chymase, molecular docking

\section{Introduction}

The genus Dictamnus has mainly five species, which grow in Europe and Asia (X. Fan, X. et 
al., 2003). Studies have found that the main active ingredients of Cortex Dictamni are fraxinellone, dictamine, obacunone, limonin, skimmianine, $\gamma$-fagarine and others (Y. Jiang et al., 2006). Plants of this genus have been reported to show various pharmacological activities, such as anti-inflammatory, antifungal, antitumor, antibacterial and antiviral effects (W.I. Jeong et al., 2006). The root bark of Cortex Dictamni has been used in Chinese folk medicine for the treatments of rheumatism, asthma, bleeding, itching, jaundice, chronic hepatitis, skin diseases and as an anti-inflammatory agent, febrifugal and detoxicant drugs (L. Wang et al., 2014). Nevertheless, there is no report on the inhibitory effects of Cortex Dictamni on DPPI or MC-chymase. Dipeptidyl peptidase I (DPPI, Cathepsin C) is lysosomal cysteine protease, which is mainly derived from neutrophils, cytotoxic T lymphocytes, and mast cell (MC) (C.T. Pham et al., 1999; W. Stout-Delgado et al., 2007). DPPI is required for the activations of elastase, cathepsin G, MC-chymase and trypsin, granzymes A/B (A.M. Adkison et al., 2002; A.M. Akk et al., 2008). Mast cell chymase is the kind of sensitive and especial serine protease (E. Tchougounova et al., 2005) , which was synthesized and released by mast cells (S. Wernersson et al., 2014). Chymase can degrade ECM and change the function of ECM when activated, regulating the stability of connective tissue and causing tissue damages (Y. Chu et al., 2017; Y. Chu et al., 2019).

The activities of DPP1 and chymase are strongly related to the development of inflammation. Inhibitors of DPPI and chymase have the potential to be an effective treatment for immunological diseases, chronic inflammation, myeloid and cytotoxic $\mathrm{T}$ lymphocyte cell malignancies and other DPPI functionally related diseases. In this study, the effects of the main chemical components of Cortex Dictamni against DPPI and chymase as the targets were analyzed in combination with the network pharmacology, and the potential molecular mechanism of DPPI and chymase targets were verified by CDAE experiments and molecular docking virtual calculation.

\section{Materials and Methods}

\subsection{Preparation of Cortex Dictamni Aqueous Extracts (CDAE)}

Cortex Dictamni was bought from a Chinese medicine shop (Tongrentang) and powdered using a new-style grinder for Chinese medicine (Changshu Chinese Traditional Medicine Machinery Co., Ltd., China). 100g of crude Cortex Dictamni powder were boiled with distilled water for 40 minutes and filtered three times with cotton gauze. The water was removed by a rotary vacuum evaporator in total filtrates of CDAE. The half solid extract concretes (from $100 \mathrm{~g}$ of crude powder) were re-suspended in total volume $50 \mathrm{ml}$ of DMEM to make $1 \mathrm{~g} / \mathrm{mL}$ backup solution of CDAE. Backup solution of CDAE was stored at $-80{ }^{\circ} \mathrm{C}$ for the night and put in a freeze-dryer for two days, then stored at $-80{ }^{\circ} \mathrm{C}$ ( $\mathrm{T}$.Wei et al., 2018 ).

\subsection{Extraction and Culture of Spleen Lymphocytes}

All the spleens of a rat were extracted, mashed and placed in the tubes containing PBS with $4 \%$ penicillin-streptomycin solution (Hyclone, USA), and then filtered through cell strainers (200mesh, Sigma, USA). The cells in the meshed spleen were dealt with Tris-NH4Cl red 
blood lysis buffer. The cells pellets were cultured in RPMI-1640 medium (GIBCO, USA) at $37{ }^{\circ} \mathrm{C}$ in a humidified incubator with 5\% CO2 atmosphere overnight to remove adherent cells. Medium contain $10 \%$ fetal bovine serum (FBS, GIBCO, USA), penicillin and streptomycin.

\subsection{DPPI Activity Assay}

The DPPI activity was examined in serum samples, cell lysates and living cells through specific substrates Gly-Phe-AFC (GF-AFC, home synthesized) (X. Liu et al., 2017) as previously described (J. Wang et al., 2017; Z. Sun et al., 2018). Firstly, $90 \mu \mathrm{L}$ of assay buffer (25 mM citric acid, $10 \mathrm{mM} \mathrm{NaCl}, \mathrm{pH} 6.0$, and $0.5 \mathrm{mM}$ GF-AFC) was mixed with $10 \mathrm{ul}$ of samples the buffer prepared in advance. The temperature is set at $36^{\circ} \mathrm{C}$, and the incubation time is set at 30 minutes. Fluorescence spectrometer (Perkin Elmer, USA) was set at Ex400/Em492nm to measure the fluorescence intensity. The fluorescence intensity change in minutes was available. The maximum kinetic rate was calculated. Michaelis-Menten equation: $\mathrm{v}=\mathrm{Vmax}[\mathrm{S}] /(\mathrm{Km}+[\mathrm{S}])$ where $\mathrm{v}$ is the initial velocity of the enzyme reaction, Vmax is the maximal velocity, [S] is the substrate concentration, and $\mathrm{Km}$ is the Michaelis-Menten constant (concentration of substrate at 0.5 of $V \max$ ) (A.R. Mceuen et al., 2008 ).

\subsection{Chymase Activity Assay}

Chymase was purified from high salt extracts of human skin tissue described previously (A.R. Mceuen et al., 1995) using heparin agarose affinity and S-200 Sephacryl gel filtration (GE Healthcare, UK) chromatography. Specific substrates, $\mathrm{N}$-succinyl-Ala-Ala-ProPhe-p-nitroanilide were used to determine the activities of chymase. The $90 \mathrm{ml}$ of working solution containing $0.5 \mathrm{mM}$ substrate mixed with $10 \mathrm{ml}$ of sample in each well. Hydrolysis of substrates was monitored and enzyme kinetic activities (Vmax) of chymase were measured by Bio-Rad micro-plate reader (L. Liu et al., 2016).

\subsection{Collection and Screening of Candidate Active Compounds in Cortex Dictamnia}

There were 99 chemical components of Cortex Dictamni searchable (L. Mu et al., 2020). Collection and screening of candidate active compounds were searched in Piper longum L.TCMSP (http://lsp.nwu.edu.cn/tcmsp.php) and ETCM. The molecular structure of each active compound was confirmed by TCMSPW database and PubChem database (https://pubchem.ncbi.nlm.nih.gov/) and transformed into the standard mol2 form.

\subsection{Molecular Docking}

Computational docking was performed to elucidate binding modes between each chemical components of Cortex Dictamni and DPPI or chymase using Discovery Studio (DS) 4.5 (Molecular Operating Environment). The crystallographic structures of proteins DPPI (PDB ID: $1 \mathrm{~K} 3 \mathrm{~B}$ ) and chymase (PDB ID: 5YJP) were retrieved from protein database website (www.pdb.org). To initiate docking study in DS 4.5, water molecules and heteroatoms were manually removed out from the protein structures. The Chemistry at Harvard Macromolecular Mechanics (CHARMM) force fled was applied and the active site was identified using cavity-based method from receptor cavities. The compound is connected with the target respectively for the Libdock molecule using the Libdock method in Dock Ligands 
module. The docking parameter is the default, the output indicator Libdock Score is collected. Then, the molecular interactions were analyzed and visualized by based on DS consensus scoring function. Hydrogen bond interactions between the ligands and active site residues were also assessed (Y. M. Zhang et al., 2019).

\section{Result}

\subsection{Effects of Cortex Dictamni Aqueous Extract (CDAE) on DPPI Activity}

The reduced cellular DPPI activities in CDAE-treated rat spleen lymphocytes were observed from time 0 to $2,8,24$, and $48 \mathrm{~h}$ after treatment compared with the cells before treatment time-dependently; while the DPPI activities in untreated cells were gradually increased (Figure 1a). The rat spleen lymphocytes were treated with DPPI $(0.025,0.050 \mathrm{mM})$, the relative growth rate (RGR \%) was increased by $50 \mu \mathrm{M}$ of DPPI, but decreased with co-treatment with CDAE $(5,50 \mathrm{mg} / \mathrm{ml})$ respectively (Figure $1 b)$. Human recombinant DPPI (hrDPPI) (Figure 1c) or the serum sample containing DPPI (Figure 1d) were mixed with different concentrations of $\operatorname{CDAE}(12.5,25,50,100 \mathrm{mg} / \mathrm{ml})$, the DPPI activities were inhibited and the inhibit rates of CDAE were increased dose-dependently.

a

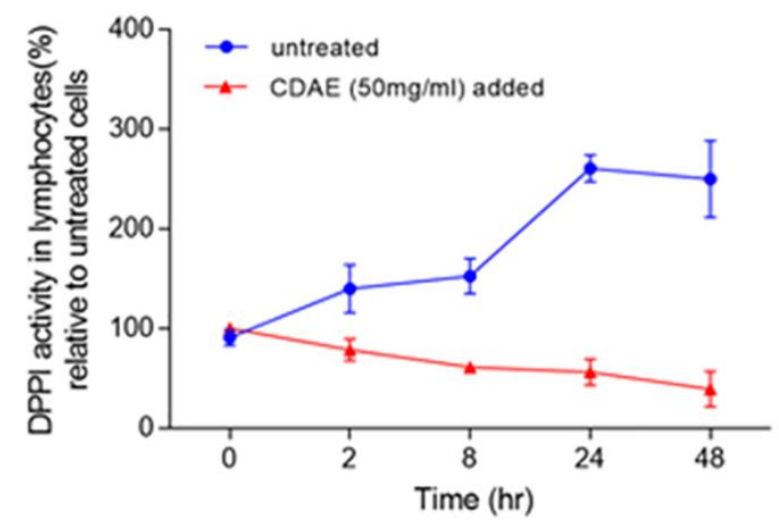

c

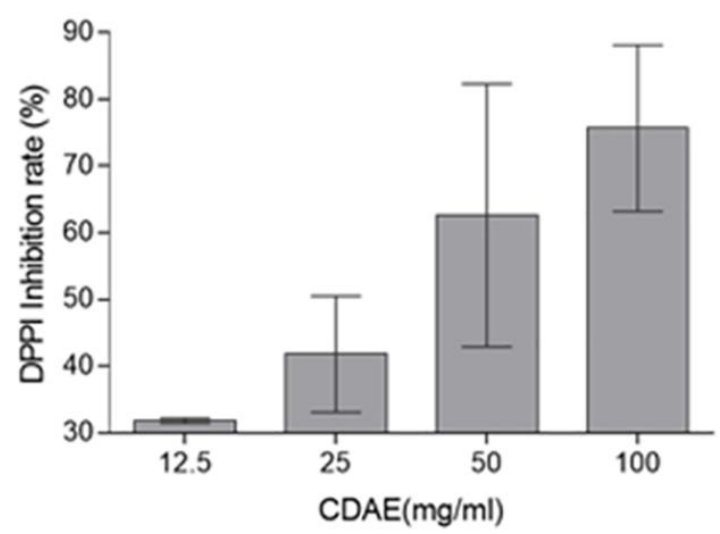

$\mathrm{b}$

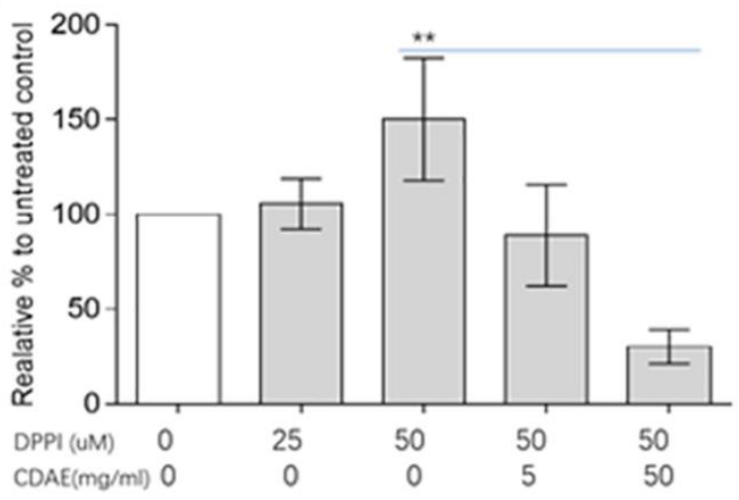

d

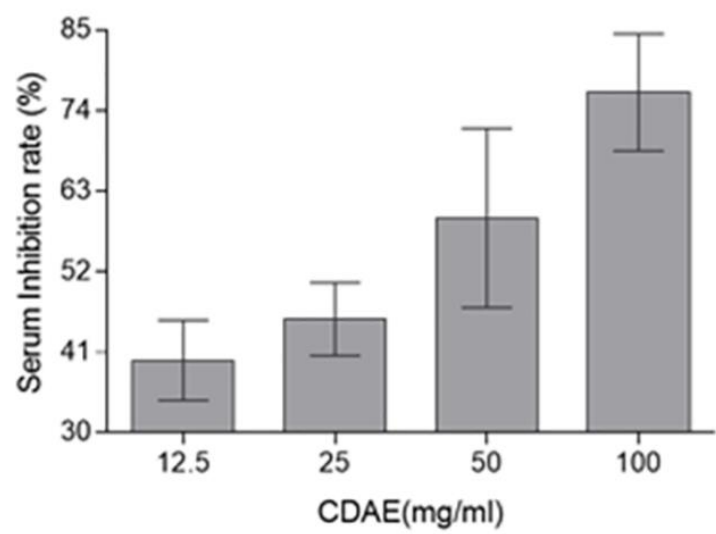

Figure.1. Dose-dependent effects of CDAE on DPPI activity and spleen lymphocytes

DPPI activities in fresh isolated spleen lymphocytes of rats before (0) and after treatments (2, 8, 24, and 48h) of CDAE (a); Changes in cell viability of spleen lymphocytes after different concentrations of DPPI $(0.025,0.050 \mathrm{mM})$ and $\operatorname{CDAE}(5,50 \mathrm{mg} / \mathrm{ml})$ treatments $(\mathrm{b})$; the 


\section{Macrothink}

inhibit rates of $\operatorname{CDAE}(12.5,25,50,100 \mathrm{mg} / \mathrm{ml})$ on hrDPPI activities relative to untreated $(100 \%)(\mathrm{c})$; the inhibit rates of $\operatorname{CDAE}(12.5,25,50,100 \mathrm{mg} / \mathrm{ml})$ on DPPI activities in serum in vitro relative to untreated $(100 \%)$ condition $(\mathrm{d}) . \mathrm{n}=3-6, * * \mathrm{p}<0.01$.

\subsection{The Effect of CDAE on Chymase Activity}

The chymase activity (Figure 2a) and serum chymase activity (Figure 2b) were inhibited by CDAE $(12.5,25,50,100 \mathrm{mg} / \mathrm{ml})$ in dose-dependent manner, with the inhibition rate gradually increasing with the increase of concentrations of CDAE.
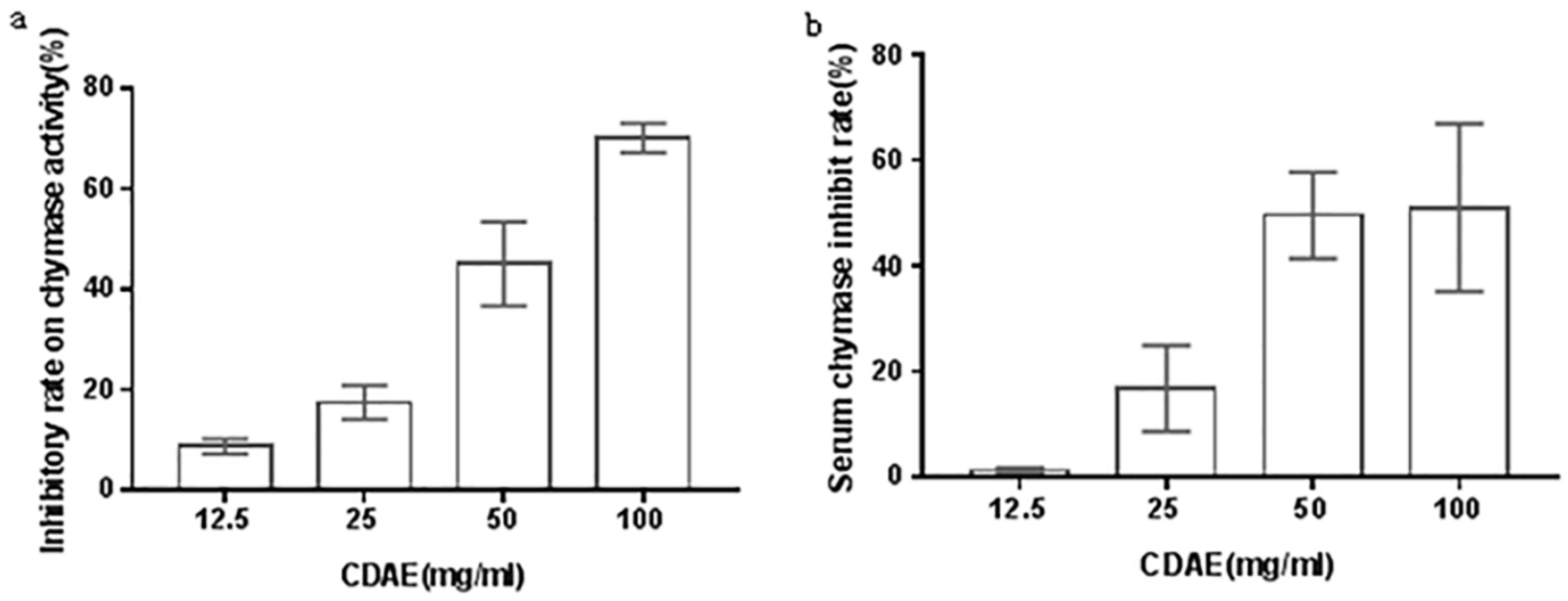

Figure.2. Dose-dependent effects of CDAE on chymase activity

The inhibitory rates of $\operatorname{CDAE}(12.5,25,50,100 \mathrm{mg} / \mathrm{ml})$ on chymase activities relative to untreated $(100 \%)$ (a). The inhibitory rates of CDAE $(12.5,25,50,100 \mathrm{mg} / \mathrm{ml})$ on serum chymase activities in vitro relative to untreated (100\%) (b). $n=3-6$.

\subsection{Molecular Docking Results}

\subsubsection{Discovery Studio Analysis of Effective Components of Cortex Dictamni for DPP1}

As shown in table 1, DPP1 was docked with 99 compounds in the Cortex Dictamni, and then four of the compounds had a good interaction with DPP1 and scored over 115. Troxerutin is active compound with the highest score (118.829) for the DPPI binding and the main anti-inflammatory substance. To gain better understanding of the correlation between inhibitors and enzymes, a docking study was performed by fitting Troxerutin into the active site of DPPI. The binding model of Troxerutin with DPPI was depicted in Figure 3a. In the Figure 3c, Troxerutin formed a hydrogen bond with amino acid ILE429 and a strong hydrophobic interaction with TYR64 CYS234 PRO279 ALA382. It could be more intuitive to see from Figure 3d. Overall, Troxerutin occupied within DPPI, exhibiting stabilizing binding conformation. 


\section{Macrothink}

Journal of Biology and Life Science

ISSN 2157-6076

2021, Vol. 12, No. 1

Table.1. Scoring the top 10 active compounds of Cortex Dictamni binding on DPPI, results were analyzed for potential inhibitor information

\begin{tabular}{|c|c|c|c|c|}
\hline $\begin{array}{l}\text { Numbe } \\
\mathrm{r}\end{array}$ & MOI ID & Name & $\mathrm{MW}(\mathrm{g} / \mathrm{mol})$ & LibDockSore \\
\hline 1 & MOL004648 & Troxerutin & 346.56 & 118.829 \\
\hline 2 & 26194552 & $\begin{array}{l}\text { (2R,3R)-3,5,7-Trihydroxy-2-(4-hydr } \\
\text { oxy-3-methoxyphenyl)-2,3-dihydroc } \\
\text { hromen-4-one }\end{array}$ & 318.28 & 118.516 \\
\hline 3 & MOL011678 & $\begin{array}{l}\text { (3S,8S,9S,10R,13R,14S,17R)-17-[(1 } \\
\text { S,4R)-4-ethyl-1,5-dimethylhexyl]-10 } \\
\text {,13-dimethyl-2,3,4,7,8,9,11,12,14,15, } \\
\text { 16,17-dodecahydro-1H-cyclopenta[a } \\
\text { ]phenanthren-3-ol }\end{array}$ & 414.79 & 117.806 \\
\hline 4 & MOL006296 & stigmast-5-ene-3 $\beta, 7 \alpha$-diol & 430.79 & 115.827 \\
\hline 5 & 398789 & Evodine & 329.3 & 114.167 \\
\hline 6 & MOL006362 & $\begin{array}{l}\text { (6S,8S,9S,10R,13R,14S,17R)-17-[(1 } \\
\text { R,4R)-4-ethyl-1,5-dimethylhexyl]-6- } \\
\text { hydroxy-10,13-dimethyl-1,2,6,7,8,9, } \\
\text { 11,12,14,15,16,17-dodecahydrocyclo } \\
\text { penta[a]phenanthren-3-one }\end{array}$ & 428.77 & 112.932 \\
\hline 7 & 101938836 & dictamnoside $\mathrm{E}$ & 374.4 & 106.176 \\
\hline 8 & MOL000006 & luteolin & 286.25 & 105.572 \\
\hline 9 & MOL000449 & Stigmasterol & 412.77 & 102.637 \\
\hline 10 & MOL006214 & Progesterone & 314.51 & 101.61 \\
\hline
\end{tabular}



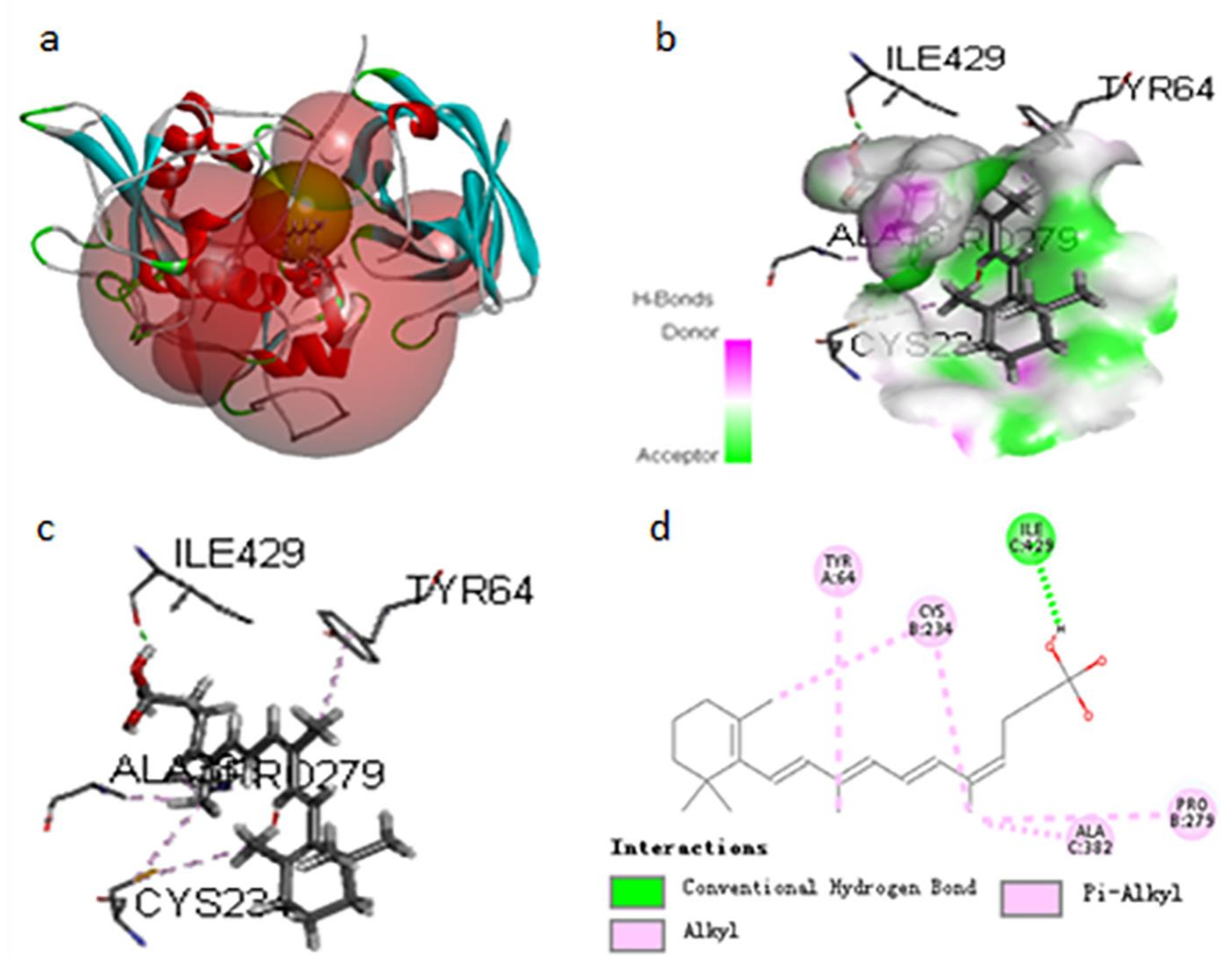

Figure.3. The binding mode of Troxerutin in complex with DPPI (PDB code 1K3B) (a). Molcad surface H-acceptor/donor density (b). Interactions between Troxerutin and residues (c)The 2D diagram of comple (d)

\subsubsection{Discovery Studio Analysis of Effective Components of Cortex Dictamni for Chymase}

As shown in table 2, chymase was docked with 99 compounds in the Cortex Dictamni, and then three of the compounds had a good interaction with chymase and scored over 130.the solo active compound, Dictamnoside $M$ is the one with the highest score (154.316) for the chymase binding. It can be seen from the Figure $4 a$, the active pocket of Dictamnoside $M$ with chymase showed a compact binding pattern. Dictamnoside $M$ has formed a hydrogen bond with amino acid ALA190, HIS57, SER218, ARG217, SER189, SER214 and a strong hydrophobic interaction with GLY193 of chymase, which are to seen from Figure 4b/c/d.All of these interactions allows Dictamnoside $\mathrm{M}$ to form a stable complex with target protein chymase. 


\section{Macrothink}

Table.2. Scoring the top 10 active compounds of Cortex Dictamni binding on chymase, results were analyzed for potential inhibitor information

\begin{tabular}{|c|c|c|c|c|}
\hline $\begin{array}{l}\text { Numbe } \\
\text { r }\end{array}$ & MOI ID & Name & $\mathrm{MW}(\mathrm{g} / \mathrm{mol})$ & LibDockSore \\
\hline 1 & 11758227 & Dictamnoside $\mathrm{M}$ & 596.7 & 154.316 \\
\hline 2 & MOL006362 & $\begin{array}{l}\text { (6S,8S,9S,10R,13R,14S,17R)-17-[(1 } \\
\text { R,4R)-4-ethyl-1,5-dimethylhexyl]-6- } \\
\text { hydroxy-10,13-dimethyl-1,2,6,7,8,9, } \\
\text { 11,12,14,15,16,17-dodecahydrocyclo } \\
\text { penta[a]phenanthren-3-one }\end{array}$ & 428.77 & 137.172 \\
\hline 3 & MOL006256 & Dictamnusine & 440.49 & 134.342 \\
\hline 4 & MOL004648 & Troxerutin & 346.56 & 128.404 \\
\hline 5 & MOL000449 & Stigmasterol & 412.77 & 127.419 \\
\hline 6 & MOL011678 & $\begin{array}{l}\text { (3S,8S,9S,10R,13R,14S,17R)-17-[(1 } \\
\text { S,4R)-4-ethyl-1,5-dimethylhexyl]-10 } \\
\text {,13-dimethyl-2,3,4,7,8,9,11,12,14,15, } \\
\text { 16,17-dodecahydro-1H-cyclopenta[a } \\
\text { ]phenanthren-3-ol }\end{array}$ & 414.79 & 126.551 \\
\hline 7 & MOL013352 & Obacunone & 454.56 & 120.343 \\
\hline 8 & 26194552 & $\begin{array}{l}\text { (2R,3R)-3,5,7-Trihydroxy-2-(4-hydr } \\
\text { oxy-3-methoxyphenyl)-2,3-dihydroc } \\
\text { hromen-4-one }\end{array}$ & 318.28 & 119.832 \\
\hline 9 & MOL006261 & Isomaculosidine & 259.28 & 119.293 \\
\hline 10 & 398789 & Evodine & 329.3 & 119.12 \\
\hline
\end{tabular}


a

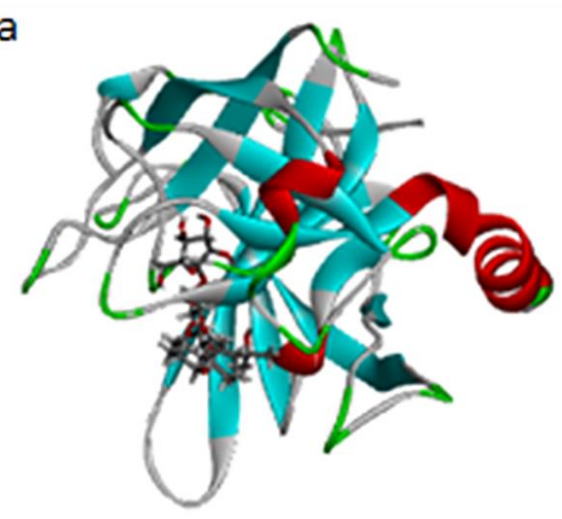

C

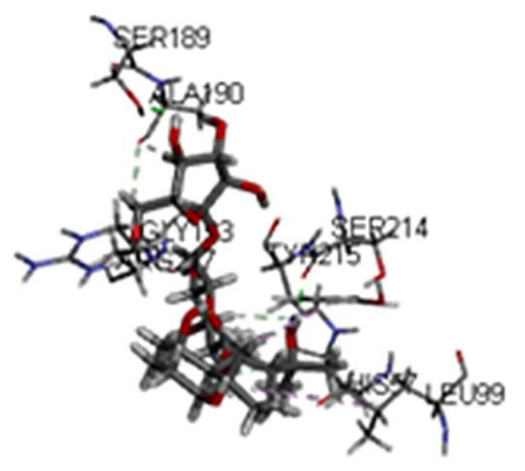

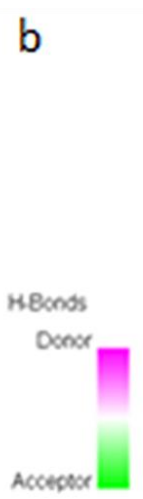

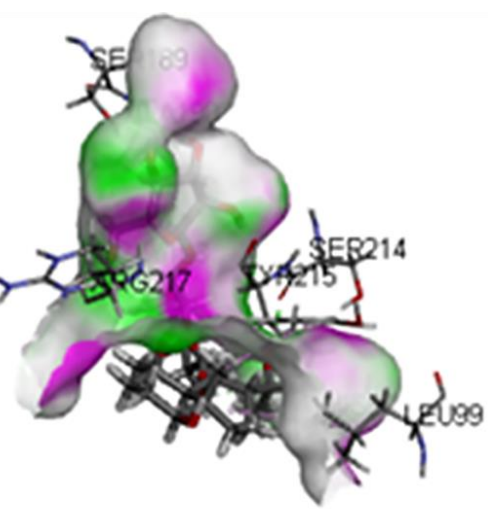

d

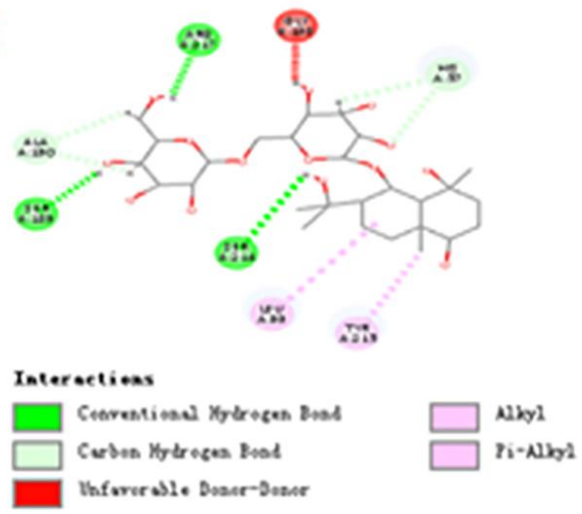

Figure.4. the binding mode of dictamnoside $\mathrm{M}$ in complex with Chymase (PDB code 5YJP) (a). Molcad surface $\mathrm{H}$-acceptor/donor density (b). Interactions between dictamnoside $\mathrm{M}$ and residues (c)The $2 \mathrm{D}$ diagram of complex (d)

\section{Discussion}

Present study showed that CDAE inhibited cell growth rates and that CDAE inhibits lymphocyte growth CDAE significantly reduced cellular DPPI activities in CDAE-treated rat spleen lymphocytes; CDAE also inhibited the activities of hrDPPI and the DPPI in serum in-vitro. CDAE suppressed the activities of human skin chymase and the chymase in serum in-vitro as well, indicating that the anti-inflammation functions of CDAE might through regulating the activity of DPPI or chymase. On the basis of the targets of DPPI and chymase, the top 10 effective components with high LibDockSore of Cortex Dictamni were screened and selected to explore the binding ability with DPPI and chymase by molecular docking virtual computing. Molecular docking is used as a computational tool to forecast the binding power and combination pattern of proteins and ligands. The "lock key model" of the mutual effect between proteins and small ligands, computing and forecasting the conformation and direction of ligands at protein active sites are the theoretical basis of Molecular docking. In this study, by referring to the relevant literature on the components of Cortex Dictamni, molecular docking was conducted, Troxerutin was selected with the highest LibDockSore (118.829) as the potential inhibitor for DPPI; and Dictamnoside M was selected with the highest LibDockSore (154.316) as the potential inhibitor for chymase. The data in table 1 and 2 further proved the accuracy and reliability of the virtual computation of network pharmacology molecules and molecular docking. DPP1 is the exonuclease and activator of 
chymase. Chymase also activates downstream MMP-2/9, and then the enzymatic cascade formed by the interaction of inflammatory enzymes in these immune cells may play an important role in the development of inflammatory disease.

Based on the preliminary experiments and the above bioinformatics screening, it is confirmed that Cortex Dictamni as an anti-inflammatory nature drug, the inhibitory functions of its aqueous extract CDAE on DPPI and chymase activities might be the underlying therapeutic mechanisms for the treatments of rheumatism, asthma, chronic hepatitis or skin diseases, etc., such granulocytes involved diseases.DPP1 and chymase activities are inhibited by CDAE, which may limit the pathological function of mast cells and related proteases upstream as a new therapeutic target. Traditional Chinese medicine (TCM) can be a good source of drug compounds in the process of drug development. Therefore, it has become one of the important ways of drug development to find the potential active compounds of relevant targets from traditional Chinese medicine. However, although Molecular docking study using SD revealed the molecular binding mechanism, but cellular level's functions of Troxerutin and Dictamnoside $\mathrm{M}$ of Cortex Dictamni, as the solo components, are still unclear at present, which needs further study. This study this study suggested a new nature inhibitor Cortex Dictamni for DPPI and chymase and its active components with the anti-inflammatory effects.

\section{Acknowledgments and Funding}

This work was supported by Changzhou Life Science Research Fund (ZMF14020066); Start-up Research-Laboratory for Oversea-Talent Fund (Z391405); Jiangsu Province Postgraduate Research \& Practice Innovation Program (KYCX19_1777); Jiangsu Province Graduate Student Scientific Research Innovation Scheme, China. No conflicts of interest.

\section{Conflict of Interest}

The authors declare that they have no conflict of interest.

\section{References}

Adkison, A. M., Raptis, S. Z., \& Kelley, D. G. (2002). Dipeptidyl Peptidase 1 Activates Neutrophil-derived Serine Proteases and Regulates the Development of Acute Experimental Arthritis, J. Cline., 109, 363-371. https://doi.org/10.1172/JCI0213462

Akk, A. M., \& Simmons, P. M., \& Chan, H. W. (2008). Dipeptidyl Peptidase I-dependent Neutrophil Recruitment Modulates the Inflammatory Response to Sendai Virus Infection, $J$. Immunology, 180, 3535-3542. https://doi.org/10.4049/jimmunol.180.5.3535

Chu, Y., Guo, Y., Zhou, X. et al. (2017). The Regulatory Role of Dipeptidyl Peptidase I on the Activation of Immune Granulocytes, Cell Biol. Int., 41(2017), 1093-1102. https://doi.org/10.1002/cbin.10815

Chu, Y., Wang, J., \& Zhou, X. (2019). Mast Cell Chymase in Synovial Fluid of Collagen-induced-arthritis Rats Regulates Gelatinase Release and Promotes Synovial Fibroblasts Proliferation via FAK/p21 Signaling Pathway. Biochemical and Biophysical 
Research Communications, 514(2019), 336-343. https://doi.org/10.1016/j.bbrc.2019.04.121

Fan, X., Zhang, S., \& Wang. A. (2003). Survey of Studies on the Chemical Constituents Pharmacological Activities of Dictamnus L. Special Wild Economic Animal and Plant Research, 25, 50-52.

Jeong, W.I., Park, O., Radaeva, S., \& Gao, B. (2006). STAT1 Inhibits Liver Fibrosis in Mice by Inhibiting Stellate Cell Proliferation and Stimulating NK Cell Cytotoxicity. Hepatology, 44, 1444-1451. https://doi.org/10.1002/hep.21419

Jiang, Y., Li, S. P., Chang, H. T., Wang, Y. T., \& Tu, P. F. (2006). Pressurized Liquid Extraction Followed by High-performance Liquid Chromatography for Determination of Seven Active Compounds in Cortex Dictamni, J. Chromatogr. An, 1108, 268-272. https://doi.org/10.1016/j.chroma.2006.01.077

Liu, L., Guo, L., Yu, C. et al. (2016). Research Progress on Chemical Components and Pharmacological Activities of Cortex Dioscorei. Proprietary Chinese medicine, 1001-1528.

Liu, X., Wang, J., Zhou, X. et al. (2017). Serum Based Fluorescent Assay for Evaluating.Dipeptidyl Peptidase I Activity in Collagen Induced Arthritis rat Model, Mol. Cell. Probes, 32, 5-12. https://doi.org/10.1016/j.mcp.2016.10.009

Mceuen, A. R., Sharma, B., \& Walls, A. F. (1995). Regulation of the Activity of Human Chymase during Storage and Release from Mast Cells: The Contributions of Inorganic Cations, pH, Heparin and Histamine, Biochim. Biophys. Acta., 1267, 115-121. https://doi.org/10.1016/0167-4889(95)00066-2

Mceuen, A. R., \& Walls, A. F. (2008). Purification and Characterization of Mast Cell Tryptase and Chymase from Human Tissues, Methods Mol. Med, 138-299. https://doi.org/10.1007/978-1-59745-366-0_25

Mu, L., Wang, L., Wang, Y. et al. (2020). Antiangiogenic Effects of AG36, A Triterpenoid Saponin From Ardisia Gigantifolia Stapf. [J], (2020). https://doi.org/10.1007/s11418-020-01427-4

Pham, C. T., \& Ley, T. J. (1999). Dipeptidyl Peptidase I is Required for the Processing and Activation of Granzymes A and B In-vivo, Proc. Natl. Acad. Sci. U. S. A., 96(1999), 8627-8632. https://doi.org/10.1073/pnas.96.15.8627

Stout-Delgado, W., Getachew, Y., Miller, B. C. et al. (2007). Intrahepatic Lymphocyte Expression of Dipeptidyl Peptidase I-processed Granzyme B and Perforin Induces Hepatocyte Expression of Serine Proteinase Inhibitor 6 (Serpinb9/SPI-6), J. Immunology, 179(2007), 6561-6567. https://doi.org/10.4049/jimmunol.179.10.6561

Sun, Z., Wei, T., \& Zhou, X. (2018). Liposomes Ecapsulated Dmethyl Crcumin Rgulates Dipeptidyl Pptidase I Ativity, Glatinase Rlease and Cell Cycle of Spleen Lymphocytes in-vivo to Attenuate Collagen Induced Arthritis in Rats. International Immunopharmacology, 511-521. https://doi.org/10.1016/j.intimp.2018.10.039 


\section{Macrothink}

Tchougounova, E., Lundequist, A., Fajardo, I., Winberg, J. O., \& Abrink, G. M. (2005). Pejler, A Key Role for Mast Cell Chymase in the Activation of Pro-matrix Metalloprotease-9 and Pro-matrix Metalloprotease-2. J. Biol. Chem., 280, 9291-9296. https://doi.org/10.1074/jbc.M410396200

Wang, J., Chu, Y., \& Zhou, X. (2017). Inhibitory effect of Tripterygium Wilfordii Polyglucoside on Dipeptidyl Peptidase I in-vivo and in vitro, Biomed. Pharmacother, 96, 466-470. https://doi.org/10.1016/j.biopha.2017.09.139

Wang, L., Li Z, L. L, et al. (2014). Acute and Sub-chronic Oral Toxicity Profiles of the Aqueous Extract of Cortex Dictamni in Mice and Rats. Journal of Ethnopharmacology, 158(2014), 207-215. https://doi.org/10.1016/j.jep.2014.10.027

Wei, T., Liu, L., \& Zhou, X. (2018). Cortex Dictamni Extracts Inhibits Over-proliferation and Migration of Rat Airway Smooth Muscle Cells via FAK/p38/Bcl-2 Signaling Pathway. Biomedicine \& pharmacotherapy = Biomedecine \& pharmacotherapie, 102(2018), 1. https://doi.org/10.1016/j.biopha.2018.03.039

Wernersson, S., \& Pejler, G. (2014). Mast Cell Secretory Granules: Armed for Battle, Nat. Rev. Immunol., 14, 478-494. https://doi.org/10.1038/nri3690

Zhang, Y. M., Wang, Y. C., \& Zhou, W. N. (2019). A Combined Drug Discovery Strategy Based on Machine Learning and Molecular Docking. Chem Biol Drug Des., 93, 685-699. https://doi.org/10.1111/cbdd.13494

\section{Copyright Disclaimer}

Copyright for this article is retained by the author(s), with first publication rights granted to the journal.

This is an open-access article distributed under the terms and conditions of the Creative Commons Attribution license (http://creativecommons.org/licenses/by/4.0/). 